\title{
BMJ Open How well are national guidelines relating to the general sales of aspirin and paracetamol, adhered to by retail stores: a mystery shopper study
}

\author{
Phillip Molloy, ${ }^{1}$ Ruth Chambers, ${ }^{2}$ Tania Cork $^{3}$
}

To cite: Molloy $P$, Chambers R, Cork T. How well are national guidelines relating to the general sales of aspirin and paracetamol, adhered to by retail stores: a mystery shopper study. BMJ Open 2016;6:e010081. doi:10.1136/bmjopen-2015010081

- Prepublication history for this paper is available online. To view these files please visit the journal online (http://dx.doi.org/10.1136/ bmjopen-2015-010081).

Received 22 September 2015 Revised 14 December 2015 Accepted 17 December 2015

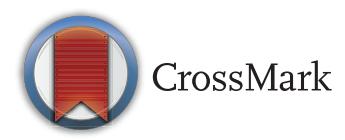

${ }^{1}$ Keele University School of Medicine, Stoke-on-Trent, UK ${ }^{2}$ NHS Stoke-on-Trent Clinical Commissioning Group/West Midlands Academic Health Science Network, Stoke-onTrent, UK

${ }^{3}$ North Staffs and Stoke Local Pharmaceutical Committee, Stoke-on-Trent, UK

Correspondence to Mr Phillip Molloy; v4z46@students.keele.ac.uk

\section{ABSTRACT}

Objective: To determine whether non-pharmaceutical retail outlets are aboding to the current Medicines and Healthcare products Regulatory Agency (MHRA) national guidelines for over-the-counter (OTC) sales of aspirin and paracetamol.

Methods: Stages 1 and 2 of the study deployed eight and four medical students, respectively, to undertake a mystery shopper style investigation. Stage 1: eight medical students attempted to buy $\geq 96$ tablets/ capsules aspirin or paracetamol in one transaction in 62 shops. Stage 2: four medical students attempted to purchase 32 paracetamol $500 \mathrm{mg}$ along with a 'flu remedy preparation also containing paracetamol, in 54 shops.

Results: Stage 1 data revealed that $58 \%$ and $57 \%$ retailers sold more than the MHRA guidelines recommended for paracetamol and aspirin, respectively. We observed that $23 \%$ and $28 \%$ retailers were willing to sell $\geq 96$ tablets of paracetamol or aspirin with no questions asked. Stage 2 results showed that $57 \%$ retailers sold $32 \times 500 \mathrm{mg}$ paracetamol in conjunction with a paracetamolcontaining 'flu preparation; while $98 \%$ shops sold $16 \times$ paracetamol $500 \mathrm{mg}$ along with a paracetamolcontaining 'flu remedy, with no questions asked of the shopper or advice given.

Discussion: MHRA national guidelines for OTC medicines sales appear to be poorly adhered to in nonpharmacy shops. Sales of aspirin and paracetamol OTC must be better regulated in the UK to ultimately reduce morbidity and mortality rates of deliberate and accidental overdoses.

\section{INTRODUCTION}

Paracetamol misuse is the number 1 cause of overdose in the UK. ${ }^{12}$ Up to 90000 presentations with paracetamol overdoses are witnessed in healthcare settings per year in the UK with around 200 associated deaths that occur annually. ${ }^{3-5}$ Deliberate overdoses are often impulsive whereby individuals take drugs that are already stored at home. ${ }^{6} 7$
Strengths and limitations of this study

- All shoppers were of similar age and background, highly motivated, trained and well briefed prior to study.

- Study collected quantitative data with qualitative evidence supporting the findings.

- Findings will have broad implications for the sales and safety of all over-the-counter medications.

- Data collection only focused on Staffordshire and Shropshire, however, large branded stores were included highlighting a potential national picture. - Internet sales was not explored.

Furthermore, many accidental overdoses result from a person with poor pain management, taking more than the recommended limit from lack of education or inadvertently exceeding the recommended dose, by taking two or more different paracetamol-containing preparations (eg, pure paracetamol and Lemsip max). ${ }^{8}$

Rising overdose rates in the 1990s, led to the UK Medicines Control Agency (now the Medicines and Healthcare products Regulatory Agency (MHRA)) consulting and advising the UK government. Consequently, new legislation introduced in September 1998 resulted in paracetamol pack size restrictions to $16 \times 500 \mathrm{mg}$ tablets/capsules/caplets at nonpharmacy retail outlets (stores without an in store pharmacy). ${ }^{9}$ The sale of over-thecounter (OTC) drugs is now commonplace with almost every newsagent, grocery and bargain store selling them. In 2009 the MHRA released further guidelines governing OTC drug sales in the UK stating "no retailer should sell more than two packets of paracetamol $(500 \mathrm{mg})$ in one transaction, retailers should be discouraged from promoting the sale of more than one pack at a time and that it is illegal to sell more than 100 tablets of 
paracetamol $(500 \mathrm{mg})$ or aspirin $(75-300 \mathrm{mg})$ in one transaction." ${ }^{10} 11$ Consequently current guidelines state that the maximum quantity recommended for OTC sale is $32 \times 500 \mathrm{mg}$ and $32 \times 75-300 \mathrm{mg}$ for paracetamol and aspirin, respectively, at non-pharmacy stores. Furthermore, the law states that no more than 100 tablets/capsules/caplets (500 $\mathrm{mg}$ paracetamol and $7.5-30 \mathrm{mg}$ aspirin) can be sold at any non-pharmacy retail outlet or pharmacy establishment in one transaction. ${ }^{10}$ Since these national guidelines were introduced (in 2009) death rates in the UK from paracetamol overdose have dropped by $43 \% .^{12}$

However, it seems that more can be done. From preliminary investigations we observed that some nonpharmacy retail outlets were selling 48 tablets/caplets of paracetamol $(500 \mathrm{mg})$ and encouraging sale of three packets $(3 \times 16$ tablets $)$ as bargain offers. This initiated the initial mystery shopper exercise to explore the extent to which a range of retailers were abiding by MHRA guidelines in non-pharmacy retail outlets (stage 1). These findings triggered further investigation (stage 2). Our aim was to assess the number of stores willing to break MHRA guidelines and the law.

\section{METHODOLOGY}

We investigated how well MHRA guidelines for limited sales of aspirin or paracetamol were adhered to in a range of retail outlets grouped as 'mainstream stores' (including Sainsbury's, Tesco, Morrisons, Asda, Co-op, Lidl, Aldi, Superdrug and Boots); and 'bargain' stores (including Poundland, Pound World, Wilko, Savers, Body Care, B and M, Premiere, 99p Store, Home bargains, Cost cutter, Pound stretcher, and other independent stores and newsagents). We aimed to gather data from at least 50 stores selected for their easy accessibility for the local population, such as town centres and on local bus routes without any exclusion criteria. Data were collected in Spring 2015.

\section{Stage 1}

Four geographical areas across Staffordshire and Shropshire were selected, hosting approximately 15 shops each selling paracetamol and aspirin; Newcastle-u-Lyme and Keele, Stoke-on-Trent and Hanley, Stafford and Stone and Shrewsbury. Sixty two shops were selected to include as many different bargain and other retail shops as possible (36 mainstream and 26 bargain stores). Eight medical students were recruited and inducted as mystery shoppers and split into four groups with one person buying aspirin and the other paracetamol from their allocated geographical area. They attempted to buy $\geq 96$ tablets/capsules/ caplets (or as many as cashiers would allow in one transaction) and an extra item of confectionary-as typical shoppers. Additionally, they were given a brief 'I'm going away for a while and suffer migraines' to use if questioned by cashiers.

\section{Stage 2}

Fifty-four non-pharmacy retail outlets in the same four locations across Shropshire and Staffordshire were selected; many similar outlets to those included in stage 1 (29 mainstream and 25 bargain stores). Four medical students were recruited and inducted as mystery shoppers each tasked with purchasing two packets of paracetamol $(16 \times 500 \mathrm{mg})$ in conjunction with one pack of paracetamol-containing 'flu remedy, and a bottle of Lucozade. They were given the brief 'My flat mate has the 'flu.' to use if questioned.

All students performed their mystery shopping tasks on different days, a few days apart within the same week. Students' time was repaid by a £30 shopping voucher with a $£ 50$ cash payment to the shopper who purchased the most OTC paracetamol or aspirin overall.

Where mainstream stores were included that contained pharmacies (8/62 stores), mystery shoppers in both stages only presented goods for payment at nonpharmacy checkouts and self-service machines. Mystery shoppers were asked in both stages to record: whether cashiers willingly allowed transactions, if any questions were asked, why any sale was refused, if cashiers would accept multiple transactions of drugs to over-ride any obstruction in payment systems, and any remarks about sales made by cashiers. All remarks were recorded immediately after sale of drugs through a spreadsheet completed by mystery shoppers. Shoppers were instructed not to attend a store more than once and avoid effervescent preparations of paracetamol and aspirin.

\section{RESULTS}

\section{Data collection}

Of the total 62 retail outlets selected selling paracetamol and aspirin in the four geographical areas, eight stores were either closed or lacked sufficient stock when mystery shoppers attempted to buy aspirin in stage 1 . Consequently data were only collected from 54 retail outlets (32 mainstream and 22 bargain stores). Fifty-four stores were identified from the original 62 in stage 1 which sold paracetamol and 'flu remedies, all of which were open and contained sufficient stocks to allow data collection and inclusion in stage 2 .

\section{Paracetamol versus aspirin sales}

Fifty-eight per cent $(36 / 62)$ of retail outlets sold more than the recommended quantity of paracetamol (32× $500 \mathrm{mg})$ in one transaction. Similarly, $57 \%(31 / 54)$ of retail outlets sold more than the recommended quantity of aspirin $(32 \times 300 \mathrm{mg})$. There were similar results for aspirin and paracetamol when analysing the purchasing of $\geq 96$ tablets/capsules in one transaction. Twenty-three per cent $(14 / 62)$ and $28 \%(15 / 54)$ of stores sold $\geq 96$ paracetamol $(500 \mathrm{mg}$ ) and aspirin $(300 \mathrm{mg})$ in one transaction, respectively. 
Table 1 Summary of total number of paracetamol $500 \mathrm{mg}$ tablet/capsule/caplet sales in stage 1 mystery shopping exercise

\begin{tabular}{|c|c|c|c|c|c|}
\hline & $\begin{array}{l}\text { Mystery } \\
\text { shops, (n) }\end{array}$ & $>32$ & $\geq 96$ & $\begin{array}{l}\text { Total } \\
\text { pills }\end{array}$ & $\begin{array}{l}\text { Average } \\
\text { number of } \\
\text { pills sold per } \\
\text { customer }\end{array}$ \\
\hline Brand 1 & 1 & 0 & 1 & 144 & 144 \\
\hline Brand 2 & 3 & 3 & 2 & 288 & 96 \\
\hline Brand 3 & 1 & 0 & 1 & 96 & 96 \\
\hline Brand 4 & 1 & 0 & 1 & 96 & 96 \\
\hline Brand 5 & 1 & 0 & 1 & 96 & 96 \\
\hline Brand 6 & 1 & 1 & 0 & 80 & 80 \\
\hline Brand 7 & 5 & 4 & 2 & 352 & 70 \\
\hline Brand 8 & 5 & 3 & 2 & 320 & 64 \\
\hline Brand 9 & 2 & 0 & 1 & 128 & 64 \\
\hline Brand 10 & 4 & 0 & 1 & 240 & 60 \\
\hline Brand 11 & 3 & 0 & 1 & 160 & 53 \\
\hline Brand 12 & 1 & 1 & 0 & 48 & 48 \\
\hline Brand 13 & 5 & 2 & 0 & 240 & 48 \\
\hline Brand 14 & 4 & 1 & 1 & 192 & 48 \\
\hline Brand 15 & 7 & 1 & 1 & 320 & 46 \\
\hline Brand 16 & 1 & 0 & 0 & 32 & 32 \\
\hline Brand 17 & 3 & 0 & 0 & 96 & 32 \\
\hline Brand 18 & 3 & 0 & 0 & 96 & 32 \\
\hline Brand 19 & 1 & 0 & 0 & 32 & 32 \\
\hline Brand 20 & 2 & 0 & 0 & 64 & 32 \\
\hline Brand 21 & 1 & 0 & 0 & 32 & 32 \\
\hline Brand 22 & 1 & 0 & 0 & 32 & 32 \\
\hline Brand 23 & 1 & 0 & 0 & 32 & 32 \\
\hline Brand 24 & 4 & 0 & 0 & 128 & 32 \\
\hline \multirow[t]{2}{*}{ Brand 25} & 1 & 1 & 0 & 32 & 32 \\
\hline & & & & 3376 & 57 \\
\hline
\end{tabular}

Some stores were willing to exceed sales of legal quantities of aspirin and paracetamol. We observed that $5 \%$ $(3 / 62)$ and $19 \%(10 / 54)$ of shops were willing to sell over 100 tablets/capsules/caplets of paracetamol and aspirin, respectively. In the extremes we observed that a single transaction of 240 aspirin $\times 300 \mathrm{mg}$ was sold from an independent store, while another 'bargain store' sold on two occasions in different towns, 144 paracetamol (500 $\mathrm{mg})$; and 168 aspirin $(75 \mathrm{mg})$ at another store elsewhere (see tables 1 and 2 and figures 1 and 2).

\section{'Mainstream' versus 'bargain' store sales of excessive aspirin or paracetamol}

Thirty-three per cent $(12 / 36)$ of the mainstream group compared to $46 \%(12 / 26)$ of the bargain store group sold >32 paracetamol $(500 \mathrm{mg})$; while $19 \%(7 / 36)$ of the mainstream group and $27 \%(7 / 26)$ of the bargain store group sold $\geq 96$ tablets/caplets/capsules of paracetamol $(500 \mathrm{mg})$ in stage 1 . Sales of aspirin showed greater disparity between the two groups of stores with $38 \%(12 / 32)$ of cashiers in the mainstream group and $86 \%(19 / 22)$ in the bargain store group selling $>32$ aspirin $(300 \mathrm{mg})$ and $16 \%(5 / 32)$ in the mainstream group and $55 \%(10 / 22)$ in the bargain store group selling $\geq 96$ aspirin $(300 \mathrm{mg})$.
Table 2 Summary of total number of aspirin $75-300 \mathrm{mg}$ tablet/capsule/caplet sales in stage 1 mystery shopping exercise

\begin{tabular}{|c|c|c|c|c|c|}
\hline & $\begin{array}{l}\text { Mystery } \\
\text { shops, (n) }\end{array}$ & $>32$ & $\geq 96$ & $\begin{array}{l}\text { Total } \\
\text { pills }\end{array}$ & $\begin{array}{l}\text { Average } \\
\text { number of } \\
\text { pills sold per } \\
\text { customer }\end{array}$ \\
\hline Brand 25 & 1 & 1 & 1 & 240 & 240 \\
\hline Brand 1 & 1 & 1 & 1 & 128 & 128 \\
\hline Brand 20 & 1 & 1 & 1 & 112 & 112 \\
\hline Brand 2 & 4 & 4 & 2 & 436 & 109 \\
\hline Brand 14 & 4 & 4 & 4 & 320 & 80 \\
\hline Brand 17 & 1 & 1 & 0 & 80 & 80 \\
\hline Brand 16 & 3 & 3 & 1 & 232 & 77 \\
\hline Brand 18 & 2 & 2 & 0 & 128 & 64 \\
\hline Brand 6 & 5 & 2 & 2 & 320 & 64 \\
\hline Brand 8 & 4 & 2 & 1 & 240 & 60 \\
\hline Brand 10 & 3 & 3 & 0 & 176 & 59 \\
\hline Brand 11 & 4 & 1 & 1 & 224 & 56 \\
\hline Brand 13 & 5 & 2 & 1 & 272 & 54 \\
\hline Brand 7 & 1 & 1 & 0 & 48 & 48 \\
\hline Brand 12 & 4 & 2 & 0 & 176 & 44 \\
\hline Brand 24 & 2 & 1 & 0 & 80 & 40 \\
\hline Brand 15 & 1 & 0 & 0 & 32 & 32 \\
\hline Brand 19 & 5 & 0 & 0 & 160 & 32 \\
\hline Brand 21 & 1 & 0 & 0 & 32 & 32 \\
\hline Brand 22 & 1 & 0 & 0 & 32 & 32 \\
\hline \multirow[t]{2}{*}{ Brand 3} & 1 & 0 & 0 & 32 & 32 \\
\hline & & & & 3500 & 70 \\
\hline
\end{tabular}

Sales of paracetamol plus 'flu remedies-containing paracetamol

We found 98\% (53/54) of shops included in stage 2 were willing to sell one packet of paracetamol $(16 \times 500 \mathrm{mg})$ in conjunction with a paracetamolcontaining 'flu remedy. Furthermore, 57\% (31/54) sold two packets of paracetamol (ie, total of $32 \times 500 \mathrm{mg}$ ) and one 'flu remedy-containing paracetamol (paracetamol content varied from 3.2 to $10 \mathrm{~g}$ within 'flu remedy packets) in one transaction, thus breaking MHRA guidelines. When comparing mystery shop transactions for the mainstream versus the bargain stores we found $52 \%(15 / 29)$ of mainstreams and $56 \%(14 / 25)$ bargain stores were willing to sell two packets of paracetamol (total of $32 \times 500 \mathrm{mg}$ ) and one 'flu remedycontaining paracetamol.

\section{Interesting comments from mystery shoppers in stage 1}

Example 1: On attempting to purchase 96 tablets $(300 \mathrm{mg})$ of aspirin one mystery shopper was asked why they needed so many. After they gave the scripted reply the cashier asked if they would like anymore. As a result the mystery shopper bought 240 tablets (15 packets of $16 \times 300 \mathrm{mg}$ aspirin) and noted that they could have bought but had to stop the cashier supplying more. This shop was an independent store.

Example 2: On attempting to buy $96(500 \mathrm{mg})$ paracetamol from an independent newsagents the mystery 


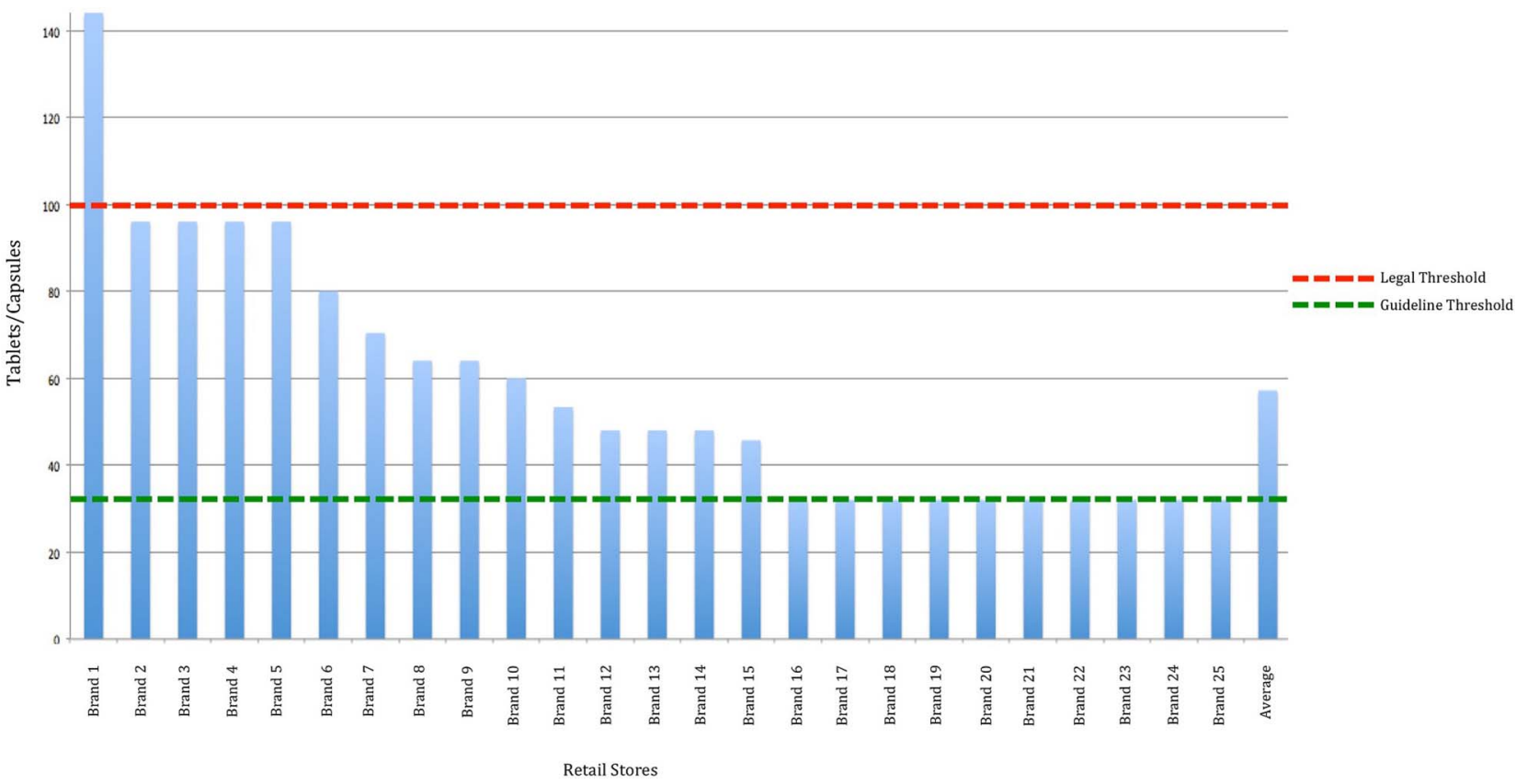

Figure 1 Average paracetamol $(500 \mathrm{mg}$ ) purchase distribution in range of store brands included in stage 1 mystery shop. This figure shows the average quantity of paracetamol sold at each brand store. The green line represents the current MHRA guidelines of 32 tablets/capsules/caplets per customer in one transaction. The red line indicated the current legal threshold of 100 tablets.

shopper was told that they could only purchase 32 that day. After hearing the scripted brief, the cashier said that they could sell them two packets (ie, $32 \times 500 \mathrm{mg}$ paracetamol) everyday until they had enough.

Example 3: When attempting to buy seven packets $(112 \times 500 \mathrm{mg}$ paracetamol) from a mainstream store at a self-service till, the checkout supervisor cleared the warning message voluntarily and over-rode it with no difficulty; so the mystery shopper was able to purchase
$112 \times 500 \mathrm{mg}$ paracetamol tablets-an illegal quantity of paracetamol in one go with no questions asked.

\section{Interesting comments from mystery shoppers in stage 2}

Answers given when mystery shoppers were refused to be allowed to purchase all three packets of medication in one transaction were: 'It's due to guidelines' (two stores), 'It's store policy' (three stores), 'It's illegal' (one store), 'Someone was sacked for it recently' (one store),

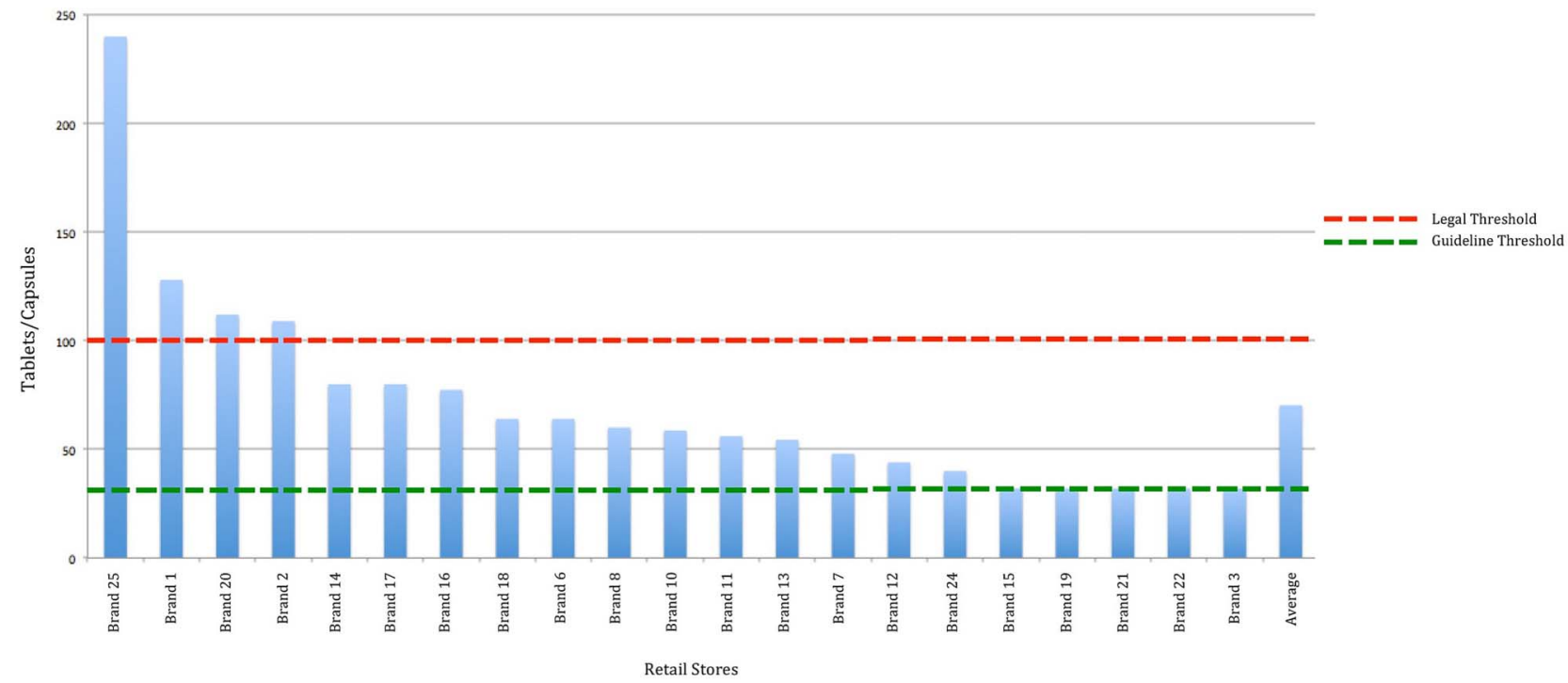

Figure 2 Average aspirin $(300 \mathrm{mg})$ purhcase distribution in range of store brands included in stage 1 mystery shop. This figure shows the average quantity of aspirin sold at each brand store. The green line represents the current MHRA guidelines of 32 tables/capsules/caplets per customer in one transaction. The red line indicated the current legal threshold of 100 tablets per customer in one transaction. 


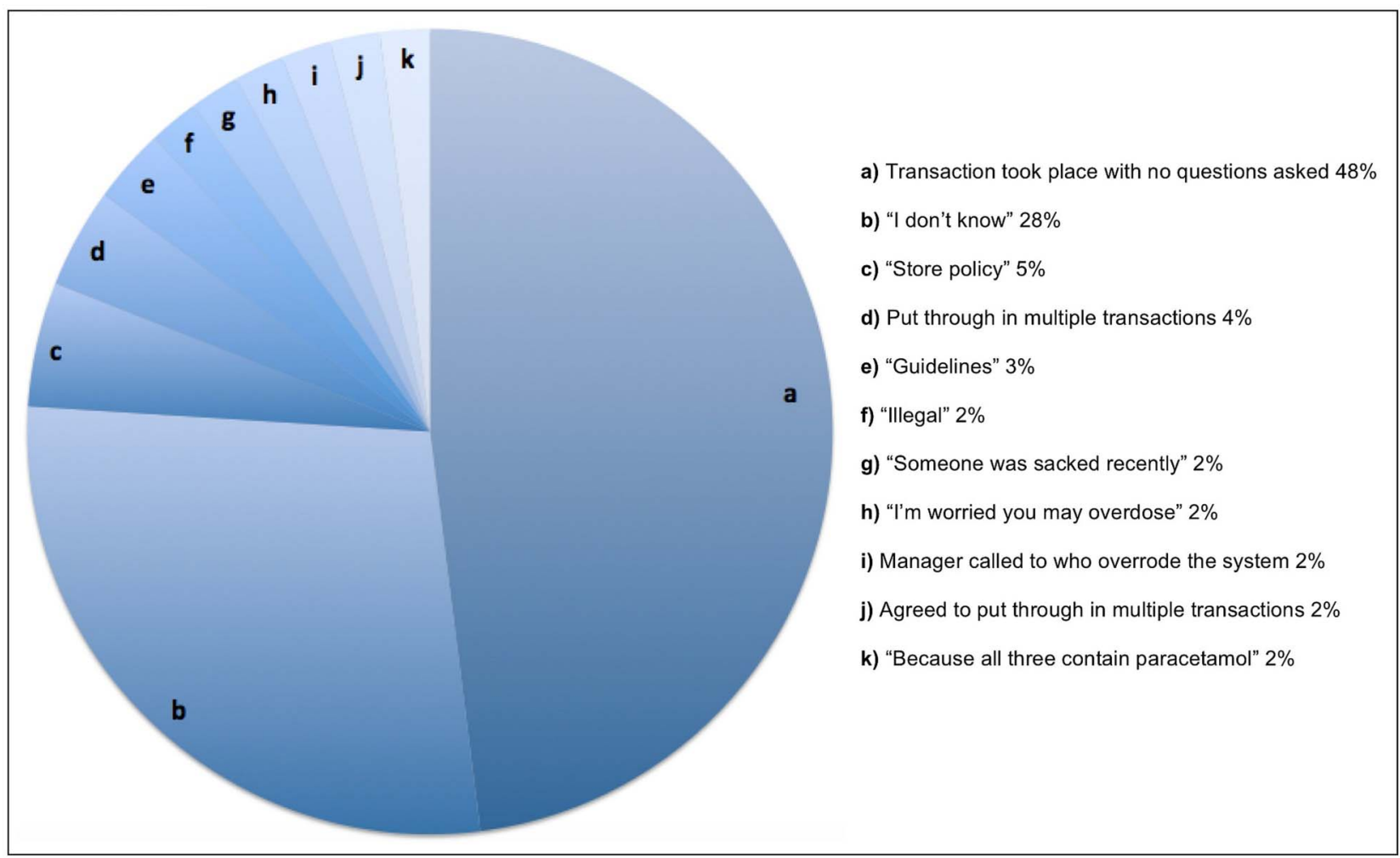

Figure 3 Comments and actions made by cashiers when purchasing aspirin and/or paracetamol in stages 1 and 2. This figure shows the comments made to mystery shoppers by cashiers when attempting to purchase paracetamol in conjunction with paracetamol-containing 'flu remedies'.

'I'm worried you may overdose' (one store) and 'I don't know why-I just can't' (15 stores). Two stores without prompting were willing to put all three packets through via two transactions, one cashier asked a manager who agreed to put the products through in two transactions, another did so after the shopper asked if it was possible, one store told the shopper that all three packs contain paracetamol and not to take them together. The remaining 24 stores put all three products through the till with no questions asked (see figure 3). Three mystery shoppers also reported that cashiers told them to go and collect another packet of paracetamol as this was on offer and it would save money, thus two shoppers purchased three packets $(3 \times 16$ of $500 \mathrm{mg})$ of paracetamol in conjunction with a paracetamol-containing 'flu remedy.

\section{Observations by mystery shoppers in stages 1 and 2}

Mystery shoppers reported that most stores (41/62) contained signs informing them that they would not sell more than 32 tablets of paracetamol (figure 4A-F). Mystery shoppers also noted display signs encouraging consumers to purchase more than two packets of paracetamol $(>2 \times 16,500 \mathrm{mg}$ ) (figure $4 \mathrm{G}, \mathrm{H})$, clearly breaching current guidelines set by the MHRA. Many OTC types of medication were placed next to everyday consumables such as shampoo, deodorants etc particularly in bargain stores. It was also observed that some stores displayed the phrase 'everyday value' beneath the products (figure 4I).
They observed variation in 'flu remedy packaging advice on paracetamol/other medication content: all types of packs purchased printed a message on the front stating the inclusion of paracetamol but the varied font size often made it hard to distinguish the word 'paracetamol' from other ingredients listed and the product's brand name. Shoppers reported that a handful of stores in the 'mainstream' group also contained pharmacies $(8 / 62)$; but checkout staff never referred shoppers to an in-store pharmacist to gain professional advice for their pain management or 'flu symptoms.

\section{DISCUSSION}

Data illustrates that regulation of OTC medication sales across Staffordshire and Shropshire is poor with around three of five shops breaching national guidelines and one in four shops encroaching or breaking the legal threshold by selling more than $\geq 96$ tablets of either paracetamol $(500 \mathrm{mg})$ or aspirin $(75-300 \mathrm{mg}$ ) in one transaction. Furthermore, a total of 13 stores sold illegal quantities of aspirin or paracetamol through selling more than 100 tablet/capsules/caplets in one transaction. There was a disparity in adherence to national guidelines between 'mainstream and 'bargain' stores. Cashiers in bargain stores tended to breach national guidelines that limit quantity of sales of paracetamol and aspirin to individual customers. We also witnessed poor regulation involving sales of paracetamol-containing 'flu 


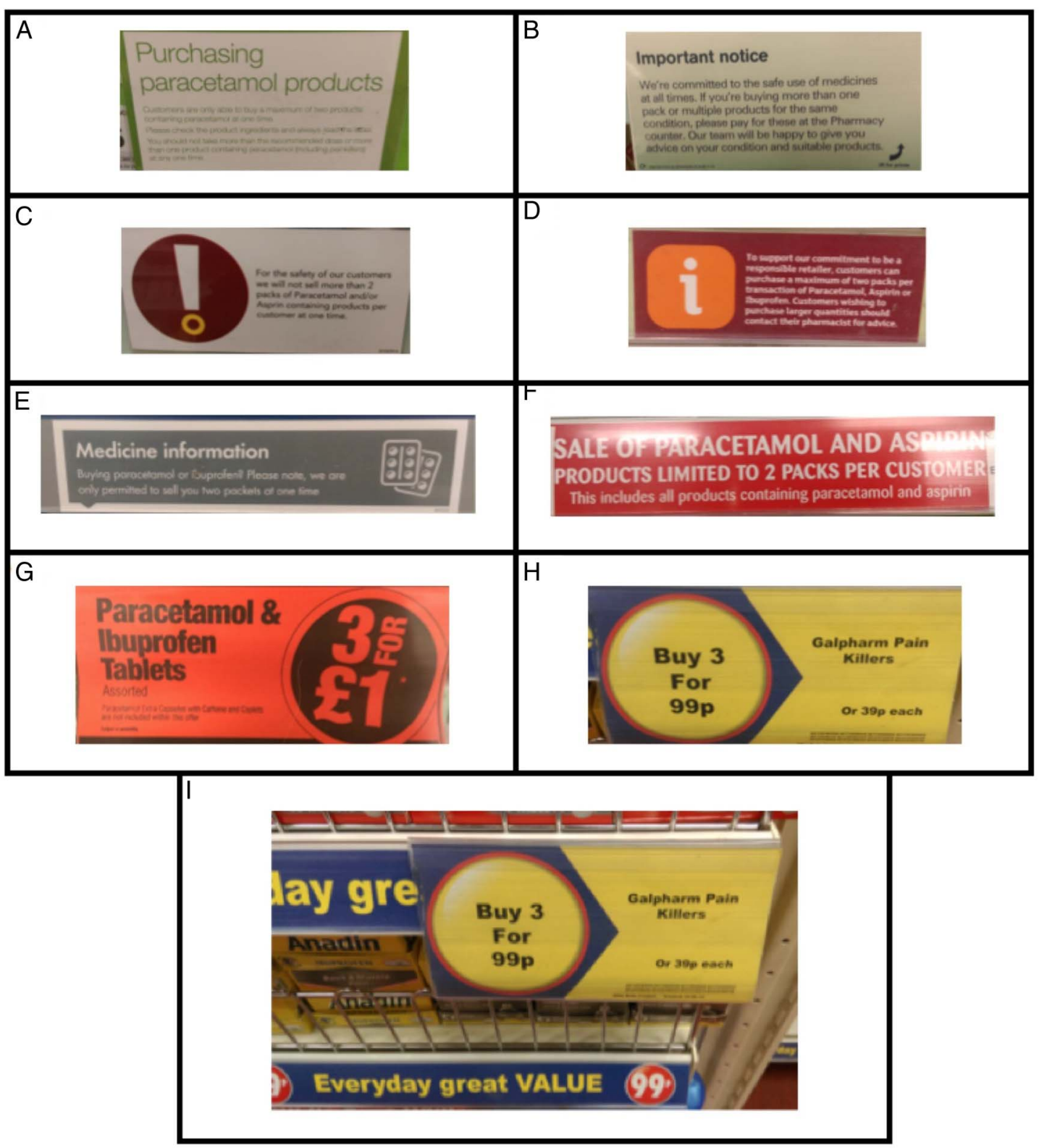

Figure 4 Signage noted as displayed in stores by mystery shoppers in stages 1 and 2 . This figure shows signs observed by mystery shoppers in various retail stores stating the refusal of more than 32 tablets/capsules/caplets of paracetamol/ibuprofen/ aspirin $(A-F)$. It also shows display signs advertising three packets of paracetamol/ibuprofen $(G$ and $H)$ and everyday value signs underneath OTCs (I).

remedies in conjunction with paracetamol-only preparations, with $98 \%(53 / 54)$ stores selling products together and only one acknowledging the potential dangers of dual use. The answers and comments given by cashiers to mystery shoppers were both alarming and interesting and, supported our original hypothesis that lay-cashiers appeared unaware of the national guidelines for the sales of medicine products (figure 3) further highlighting the potential dangers of OTC medication use. It is very concerning that retail shops are selling these preparations without warnings to their customers and often in excessive quantities.

Despite many shops displaying customer information stating the sale restrictions, a significant proportion of stores were breaching MHRA guidelines and the law, seemingly unknowingly. Cashiers seemed unaware why guidelines exist ${ }^{13}$ and so were willing to break recommendations or find loop holes for themselves or customers, such as to return to the same shop everyday to buy the maximum amount. There was absolute disregard for patient safety when an independent store was willing to sell almost 2.5 times the legal quantity of aspirin $(240 \times 300 \mathrm{mg})$. This attitude and commercial behaviour cannot and should not be tolerated as it makes overdosing with paracetamol or aspirin potentially more likely for the general public.

Another concerning observation was the lack of public safety and protection at self-service checkouts by the 
absence of alerts. Some shoppers were able to buy 112 tablets/capsules/caplets paracetamol (500 mg) at mainstream stores without any screen messages warning them not to, or alerting self-service supervisors. Mystery shoppers found that until systems could be manually overcome to not just breach guidelines but also break the law. We therefore suggest that all stores set up arrangements preventing sales of more than 32 paracetamol $(500 \mathrm{mg})$ or aspirin $(300 \mathrm{mg})$ in one transaction.

Another concern was the use of 'every day' value signs underneath OTC medications and their placement next to commonly purchased consumables such as beauty products. The psychology that these medications are consumables rather than potentially harmful drugs is worrying. By shops shifting medications away from these signs and everyday products, customers may recognise that these medications are not for everyday use and should be used with caution. This mentality that paracetamol is not dangerous has been highlighted in the media several times in recent years, with many reports detailing how victims took multiple tablets in order to treat pain without realising the dangers of paracetamol overdose or other OTC drugs. ${ }^{14-17}$ There has recently been a huge campaign to stop young people participating in the '\#paracetamolchallenge', whereby children encouraged and dared one another over social media to take multiple paracetamol before uploading images to social media networks. This craze has hospitalised numerous young persons with potentially life-long liver damage. ${ }^{18}$ This again highlights wide scale public ignorance of paracetamol dangers.

The $98 \%(53 / 54)$ of retail outlets selling $16 \times 500 \mathrm{mg}$ paracetamol tablets/capsules in conjunction with a paracetamol-containing 'flu preparation without any guidance that such medications contain paracetamol was extremely alarming. Stores should not be allowed to sell different preparations-containing paracetamol without adequate warning (eg, verbally informing customers that both products contain paracetamol and should not be taken in conjunction with one another). Pharmacists are trained healthcare professionals who are skilled in informing customers about potential dangers of medication and will make clinical decisions to withhold sale of medication if they do not feel it is warranted. While we appreciate this decision process cannot be made by lay cashiers, the explanation that both products contain paracetamol could be easily implemented by integrating into till systems and staff training.

Reliance on lay advice at checkouts in stores selling paracetamol (even when a pharmacy is elsewhere in-store) may result in significant harm and morbidity which is likely avoidable with proper education of staff. This strengthens the case to explore the benefits of store staff education concerning the potential dangers of selling more paracetamol in one transaction, than guidelines permit on their health customers. It seems bizarre that alcohol and tobacco are highly regulated and OTC medications are not. ${ }^{19}$ We would therefore like to see
OTC medications included in the store's training programme for all staff. We would recommend unannounced inspections in relation to internal or external regulation of paracetamol and/or aspirin sales, through the use of test purchases similar to those used for alcohol and tobacco. The MHRA should initiate action on stores that breach guidelines or legal limits on paracetamol and/or aspirin sales with similar punitive measures as those for tobacco and alcohol mis-sales.

Finally, while we appreciate we have only investigated a small proportion of stores nationally, previous studies elsewhere have shown similar results concerning paracetamol, and as our mystery shopping exercise spanned two counties we can assume that this has provided a good snapshot of what is happening nationally. ${ }^{20}$

This lack of automatic questioning of customers with paracetamol in their checkout baskets, by poorly trained staff at non-pharmacy retail outlets or checkouts does jeopardise many customers' safety.

\section{Concluding remarks}

Mystery shopper findings justify a much needed change to protect consumers from careless selling of OTC medications on a wide scale across the UK, and tougher regulation of stores breaching guidelines and legal limits on the maximum quantity of paracetamol or aspirin sold in one transaction to the same customer. Such widespread failure of OTC regulation compromises public safety, resulting from the apparent lack of retail store staff education, poor fail-safe systems at checkouts and limited information given to customers on packaging and by sales staff.

Studies investigating the source of overdoses almost a decade ago showed very similar results; however, there has been insufficient change in the MHRA guidelines, ${ }^{20}$ and ' 3 for 2' bargain offers of paracetamol are simply dangerous. The combination of poor consumer education concerning potential dangers of excessive use of pain relief medication, an ageing population, pressures from an ever busier National Health Service (NHS) system that encourages self-care, and this potential nonadherence to national best practice guidelines will continue to underpin a high number of avoidable paracetamol-induced deaths. If national guidelines and regulations were enforced, so preventing the large sales of OTC medication in one transaction, it is likely that stockpiling of paracetamol in consumers' homes will be far less. Consequently, individuals are less likely to take excessive quantities of paracetamol which is easily to hand, in a deliberate overdose in response to a sudden crisis. As a result, their chances of survival will be increased, morbidity decreased with enhanced clinical outcomes and reduced avoidable healthcare usage.

Mystery shopper findings also revealed that ingredients such as paracetamol were not generally clearly defined on the front of 'flu remedy packs. We therefore recommend that the front covers of all packaging contain an easy to read alert relating to paracetamol 

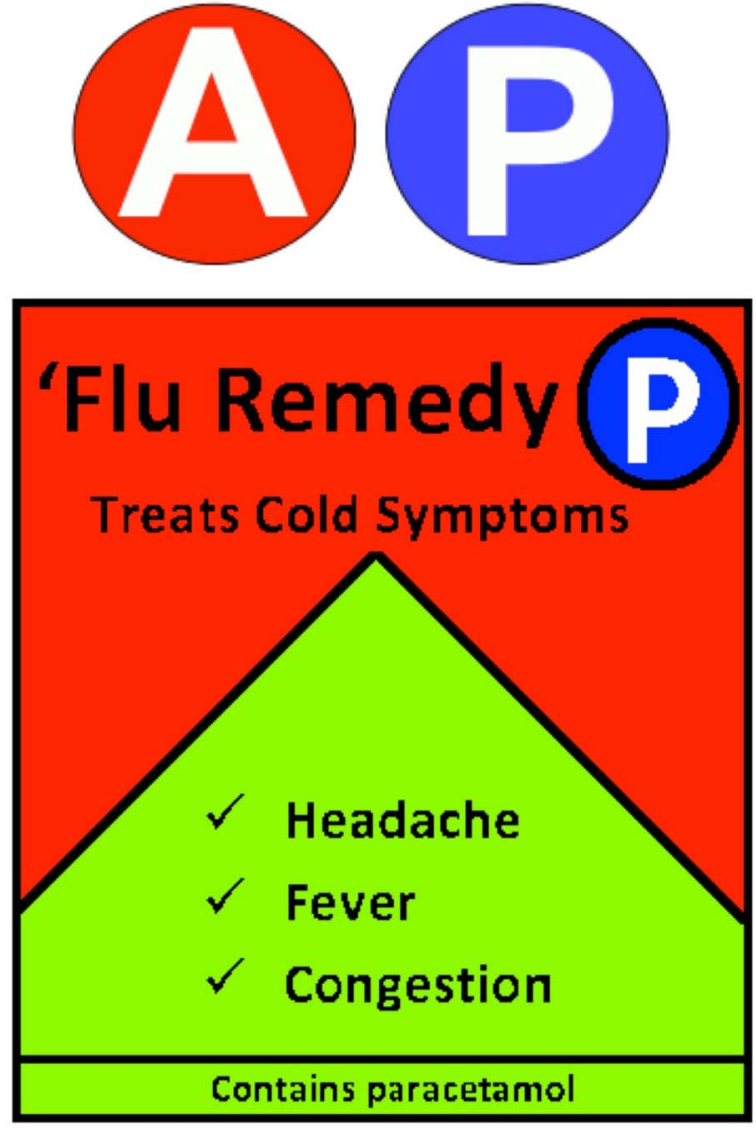

Figure 5 Proposed logos to be used for OTC medication packaging to highlight paracetamol and aspirin ingredients. This figure demonstrates proposed logos to include on OTC medication products-containing aspirin (top left) and paracetamol (top right). The logo has been incorporated onto a product to display how we propose it could be used (bottom).

content, which is consistent for all brands, of sufficiently a large font size that it can be read by most people without glasses (eg, font size $\geq 14$ ). We also recommend the introduction of a nationalised logo indicating products-containing paracetamol or aspirin to avoid accidental misuse of multiple preparations (figure 5). The logo should also be raised to provide tactile identification for blind and visually impaired people. This implementation would simplify packaging, make customers more aware of these ingredients and be understandable to those with poor literacy skills.

MHRA or another national oversight group might consider setting guidelines for paracetamol content; so rather than 'flu remedy content varying from 300 to $1000 \mathrm{mg}$ paracetamol dose content be adjusted to include the same standard quantity of paracetamol with associated advice about the maximum 'pure' paracetamol that can be taken within for example, 6 hours of the paracetamol-containing 'flu remedy. Thus, pain or temperature control management would be achieved and individuals would have a decreased risk of overdose through ignorance of dangers of paracetamol content in multiple preparations.

We therefore urge the MHRA to review our recommendations and industries and retailers to change their policies and systems for example, signpost customers to pharmacists who request substantive paracetamol or other pain relieving medication such as codeine, utilising their knowledge especially if stores contain an in-house pharmacy. Finally, we want to assure readers that our recommendations have been passed onto the MHRA and we encourage their support to drive change. Furthermore, all retail stores included in our study have been informed with detailed descriptions of potential flaws that we identified in their normal operating procedures.

\section{Limitations}

Owing to the varying packet size of paracetamol/aspirin medication and product availability especially in some smaller stores, mystery shoppers were unable to purchase identical amounts or types of medication (capsules/tablets/sachets; or manufacturer). Packet quantity varied from multiples of 8, 12, 16 and 20 tablets/capsules/caplets/sachets. In some cases this limited availability restricted large sales due to small quantities of stock. Furthermore, some shoppers reported only attempting to buy 96 tablets rather than $>100$ due to pack size restrictions. Along with pack size, strength of aspirin also varies. Many of the bargain stores sell $75 \mathrm{mg}$ aspirin as opposed to the $300 \mathrm{mg}$ commonly sold in shops in the mainstream category. However, MHRA guidelines are the same regarding number of aspirin tablet/capsules/caplet sales whatever the strength. Eight different people were also used to purchase drugs in stage 1 and four others in stage 2. All mystery shoppers were of similar ages (21-27 years); but despite their induction, they may have used slightly different techniques and approaches to purchase drugs. Despite using well-motivated cohorts of student shoppers we recognise that the bonus cash incentive may have motivated shoppers to varying degrees.

We also encountered issues when collecting data. Eight stores were either out of stock or closed during stage 1 aspirin data collection. Similarly, eight stores did not stock paracetamol and paracetamol-containing 'flu remedies when conducting the stage 2 mystery shop. Data collection was limited to seven towns in four geographical areas around Staffordshire and Shropshire including a small percentage of stores that were easily accessible to the local population and would have had aspirin, paracetamol and 'flu remedies for sale.

Finally, we did not investigate as part of our study online purchases of OTC medications. This is an area which has been explored and highlighted as a potential medium to easy access of OTC medications. ${ }^{21}$ 


\section{Key recommendations}

1. Establish new laws:

a. Illegal to sell $>32$ paracetamol at non-pharmacy counters.

b. Non-pharmacy counters not permitted to sell paracetamol and paracetamolcontaining medications in conjunction with one another.

2. Establish improved staff training and guidelines for sale of paracetamol and/or aspirin.

3. Regulate OTC medication purchases internally/externally.

4. Improve all till systems to prevent $>32$ paracetamol tablet/ capsule sales or in conjunction with other products containing paracetamol.

5. Remove OTC medications away from everyday value signs and commodities.

6. Produce a standardised visual identification logo to indicate if a product contains paracetamol or aspirin (see figure 5).

Acknowledgements The authors would like to thank all mystery shoppers for their time and effort and Dr Ross Wilkie for methodological and statistical advice.

Contributors PM conducted the systematic review, study design, collection, interpreted, analysed the data, drafted and edited the manuscript. RC contributed to the study design, edited the manuscript and reviewed final versions of the manuscript. TC contributed to the study design and edited the manuscript.

Funding This work was funded by the West Midlands Academic Health Science Network and Grünenthal Pharmaceutical Ltd who awarded PM a national prize ( $£ 3000)$ for patient-centred pain management for work undertaken in stage 2 .

Competing interests None declared.

Ethics approval Ethical approval was granted by Keele University School of Medicine Ethics Committee for stage two. Ethics approval was not requested for the stage one mystery shopping exercise.

Provenance and peer review Not commissioned; externally peer reviewed.

Data sharing statement Additional data can be accessed via the Dryad data repository at http://datadryad.org/ with the doi:10.5061/dryad.b1k0v.

Open Access This is an Open Access article distributed in accordance with the Creative Commons Attribution Non Commercial (CC BY-NC 4.0) license, which permits others to distribute, remix, adapt, build upon this work noncommercially, and license their derivative works on different terms, provided the original work is properly cited and the use is non-commercial. See: http:// creativecommons.org/licenses/by-nc/4.0/

\section{REFERENCES}

1. Gunnell D, Murray V, Hawton K. Use of paracetamol (acetaminophen) for suicide and nonfatal poisoning: worldwide patterns of use and misuse. Suicide Life Threat Behav 2000;30:313-26.
2. Hawton K, Simkin S, Deeks J, et al. UK legislation on analgesic packs: before and after study of long term effect on poisonings. BMJ 2004;329:1076.

3. McQuade D, Dargan P, Keep J, et al. Paracetamol toxicity: what would be the implications of a change in UK treatment guidelines? Eur J Clin Pharmacol 2012;68:1541-7.

4. Thompson G, Fatima S, Shah N, et al. Impact of amending the acetylcysteine marketing authorisation on treatment of paracetamol overdose. ISRN Toxicol 2013;2013:1-5.

5. Bateman D, Carroll R, Pettie J, et al. Effect of the UK's revised paracetamol poisoning management guidelines on admissions, adverse reactions and costs of treatment. Br J Clin Pharmacol 2014:78:610-18.

6. Hawton $\mathrm{K}$, Ware $\mathrm{C}$, Mistry $\mathrm{H}$, et al. Paracetamol self-poisoning. Characteristics, prevention and harm reduction. Br J Psychiatry 1996;168:43-8.

7. Hawton $\mathrm{K}$, Ware $\mathrm{C}$, Mistry $\mathrm{H}$, et al. Why patients choose paracetamol for self poisoning and their knowledge of its dangers. BMJ 1995;310:164.

8. Ferner RE, Dear JW, Bateman ND. Management of paracetamol poisoning. BMJ 2011;342:d2218.

9. Committee on Safety of Medicines MCA. Paracetamol and Aspirin. Curr Prob Pharmacovigilance 1997:23:9.

10. [Internet]. (cited 7 May 2015). 2009. http://www.mhra.gov.uk/home/ groups/comms-po/documents/news/con065561.pdf

11. Rpharms.com. Royal Pharmaceutical Society I Aspirin legal status table. (cited 6 May 2015). 2015. http://www.rpharms.com/ legal-classification-of-medicines-db/aspirin-legal-status-table. asp

12. Hawton $\mathrm{K}$, Bergen $\mathrm{H}$, Simkin $\mathrm{S}$, et al. Long term effect of reduced pack sizes of paracetamol on poisoning deaths and liver transplant activity in England and Wales: interrupted time series analyses. BMJ 2013;346:4403.

13. [Internet]. (cited 6 December 2015). 2015. http://www.legislation.gov. uk/uksi/2012/1916/regulation/236/made

14. Mail Online. Student, 17, sold lethal paracetamol dose by Tesco. (cited 12 June 2015). 2015. http://www.dailymail.co.uk/news/ article-387953/Student-17-sold-lethal-paracetamol-dose-Tesco.html

15. Mail Online. Woman accidentally killed herself with overdose of painkillers. (cited 1 July 2015). 2015. http://www.dailymail.co.uk/ news/article-2940913/Woman-killedaccident-overdosing-painkillers-suffered-severe-earache.html

16. BBC News. Paracetamol death: Desiree Phillips died after taking too many, inquest told-BBC News. (cited 1 July 2015). 2015. http://www.bbc.co.uk/news/uk-wales-south-west-wales17309666

17. Willey J. Painkiller paracetamol's 'link to liver failure'. Express.co.uk. (cited 1 July 2015). 2011. http://www.express.co.uk/news/uk/223266/ Painkiller-paracetamol-s-link-to-liver-failure

18. Khomami N. Police issue warning over paracetamol challenge. The Guardian. (cited 25 June 2015). 2015. http://www.theguardian com/society/2015/June/12/police-warning-paracetamol-challenge

19. [Internet]. (cited 6 December 2015) 2015. https://www.asa org.uk/ News-resources/Hot-Topics/Alcohol.aspx\#.VmRHnEljEZZ

20. Greene SL, Leman PI, Jones P. Paracetamol availability and recent changes in paracetamol poisoning: is the 1998 legislation limiting availability of paracetamol being followed? Postgrad Med $J$ 2006;82:520-3.

21. Hewett DG, Shields J, Waring WS. Missed paracetamol (acetaminophen) overdose due to confusion regarding drug names. Curr Drug Saf 2013;8:203-6. 